\title{
Nanoparticles for the Treatment of Lung Cancers
}

\author{
Raahulan Sivarajakumar, Dhamini Mallukaraj, Madhurya Kadavakollu, Niveditha Neelakandan, Sandhya Chandran, Saravanan Bhojaraj, \\ Veera Venkata Satyanarayana Reddy Karri* \\ Department of Pharmaceutics, JSS College of Pharmacy, Ootacamund, JSS Academy of Higher Education and Research, Mysore, Karnataka, INDIA.
}

\begin{abstract}
On the row of various cancers in the world, the Lung cancer falls to number two in both female and male. Various surgical and non-surgical therapeutic approaches including chemotherapy, photodynamic therapy, and radiotherapy are employed in the treatment of lung cancer. However, most of these techniques are costly, complex and lacks patient compliance. In case of chemotherapy, it is associated with lack of specific tumour targeting, with limited drug solubility leads insufficient amount of drug reaches to a tumor site. To overcome these demerits associated with chemotherapy, various types of nanoparticles (both organic and inorganic) are synthesized and studied in treating lung cancers. In this article, we have reviewed the various types of nanoparticles that have been used in treating lung cancers. This review was carried out by searches of relevant published articles, reviews and abstracts in PubMed/Medline, Web of Science, clinicaltrials.gov, Cochrane Database of Systematic Reviews and Google Scholar of all English
\end{abstract}

language articles. The following search terms were used: Lung cancer, Target delivery, animal models, Nanoformulation, Nanoparticles and Polymeric Nanoparticles.

Key words: Nanoparticles, Lung cancer, Target delivery, Nanoformulation, Polymeric Nanoparticles.

Correspondence

Dr. Veera Venkata Satyanarayana Reddy Karri, Department of Pharmaceutics, JSS College of Pharmacy, Ootacamund, JSS Academy of Higher Education \& Research, Mysore, Karnataka, INDIA.

Phone: +919952478866

Email: ksnreddy87@gmail.com

DOI: 10.5530/jyp.2018.10.62

\section{INTRODUCTION}

The term cancer denotes the abnormal growth of the cells, which takes in oxygen and nutrients from other living cells. The cancer cells lose its cell adhesion with other living cells and spread to other parts of the body through the bloodstream and initiate the development of the secondary tumor growth. The tumour can be removed from its early stage of growth from the body. ${ }^{1}$ Most of the cancer death patients under go metastasis of various cancers like lungs, liver and bone. The malignancy has a hyper capacity of replication of cells in the rapid formation of the bloodstream. In contrast to malignancy, the metastasis cancer can be cured to some extent. Closely 200 types of cancers are existing on various symptoms. This is due to various life factors like lifestyle, age, and genetic causes. On this existing cancers lung cancer is the most widely spread cancer all around the world ${ }^{2}$ which is reported by UK Cancer Research in 2011.

\section{Bronchogenic Carcinoma}

On the row of various cancers in the world, the lung cancer falls to number two in both female and male. The primary function of the lungs is exchange of the gases between the air and blood. Moreover, the purification of the blood expelling carbon-di-oxide and in spelled oxygen takes place nearly 95\%. Bronchogenic cancer exactly occurs in epithelial cells and it is also called as lung cancer. It is divided into four major categories by WHO in 1982: (a). Adenocarcinoma (AD), (b). Squamous cell carcinoma (SCC), (c). Large cell carcinoma (LC), (d). Small cell cancer (SCC). These four were segregated into two major categories as (a). Small cell lung carcinoma (b). Non-small cell lung cancer which comprises AD, SCC and LC. It is difficult to cure the small cell lung cancer the most aggressive cancer compared to non-small cell lung cancer. The small cell lung cancer occurs due to the huge intake of tobacco, inhalation of radon gas and consumption of arsenic in drinking water. The bronchi are the place where the small cell lung cancer produced from the inner layer of the wall. The earlier symptoms of lung cancer are hoarse throats, chest pain, respiratory infections, and difficulty in breathing. Transformation of the primary stage symptoms to secondary stage causes coughing with blood laden sputum, fatigue, difficulty in swallowing and Jaundice. ${ }^{3}$

\section{PATHOLOGY OF LUNG CANCER}

The lung is a fragile complex organ compared to many cells types with different functions that favor gaseous exchange. $2,000 \mathrm{~km}$ of the airway and more than $50 \mathrm{~cm}^{2}$ of the extremely thin alveolar membrane which enhances efficient passage of $\mathrm{O}_{2}$ and $\mathrm{CO}_{2}$. Large inhaled particulates are cleared by ciliary action in large airways and infectious agents are eliminated by immune and phagocytic cells. ${ }^{4}$ Cells undergo an accumulation and micro environmental adaptions that alter the balance of cell division and death leads to cancer. Years of exposure to tobacco smoke resulting in structural damage to chronic obstructive lung pulmonary disease and emphysema. Due to smoking, morphological changes of bronchial epithelium progressing from basal cell hyperplasia to metaplasia, severe dysplasia to carcinoma (in-situ) and finally carcinoma. Adenocarcinoma, heavy lung damage and its dominant subtypes in never smokers with low carcinogen exposure. ${ }^{5}$ The progress of adenocarcinomas is associated with less well characterized pre-malignant lesions called atypical adenomatous hyperplasia. Pathological classification of lung cancer is continually changing, with a need for specific terminology and criteria to distinguish squamous cell carcinoma from adenocarcinoma, particularly poor differentiated tumors. ${ }^{6}$

\section{TREATMENT OF LUNG CANCER}

The basic choice of therapy depends upon the size of cancer and its location. Lung cancer can be treated with various methods such as surgery, radiation therapy, photodynamic therapy, and chemotherapy and target specific therapy. 


\section{Surgery}

The surgery is completely restricted to the patient that has serious heart and lung disease. The surgery is performed basically for stage-I and II type of Non-small cell lung cancers. Three majorly employed techniques for removal of lung cancer include (a). Lobectomy (removal of lung lobe), (b). Wedge resection (removal of mass harmful tissues of the lung), (c). Pneumonectomy (removal of lungs). Generally, 10-35\% of lung cancer can be cured with surgery but not complete eradication. Towards Small cell lung cancer, the surgery is not possible because of its presence in one specific location which is difficult to operate. Whereas, Non-small cell lung cancer can be cured in such a manner it has not spread beyond the lungs. ${ }^{\text {? }}$

\section{Radiation Therapy}

The radiation therapy is used to shrinkthe tumor size but complete eradicationis difficult. In ration therapy initially the tumour size is reduced using high energy X-Rays/Ionizing Radiation such as Radium (228 Ra), Iridium (192 Ir), Phosphorus (32 P), Cobalt (60 Co) followed by surgery for the removal of remaining harmful cells. The radiation therapy is generally categorized into two types (a). Brachytherapy (radioactive source in pellets is placed close to cancer cells), (b). Tele-therapy (source placed outside the body (Irradiate). The major side effects are fatigue, reduction of White Blood Cells (WBC). If the patient is very sensitive to the radiation they may have nausea, vomiting, skin irritation.?

\section{Photodynamic Therapy (PDT)}

The Porfimer sodium is the First-Generation Photosensitizer where it is widely used for the diagnose of the lung cancer. The PDT is the organic photo-sensitive agent (Porphyrin, Texaphyrin and Chlorine). When the photosensitizers incorporated into the specific site with the help of the external light with specific wavelength they elevate to the ground state to excited singlet later to triplicate state. Where oxygen plays a major role, it stays in the ground triplet state. In the account of this singlet oxygen are more highly reactive helps to destroy the cancer cells. This PDT is likely useful in the diagnosis. ${ }^{8}$

\section{Chemotherapy}

The various drugs approved by USFDA for lung cancer are shown in Table 1.

The main limitations of current chemotherapy for the treatment of lung cancers are lack of target specificity, recurrence and superficial increase in lifespan of human beings. Further, oral and IV administrations of the anti-cancer drugs have many drawbacks such as Degradation of the drug molecule in the stomach $\mathrm{pH}$, alterations in the drug molecule during the process of metabolism in the liver, lack of specificity in the conventional method of treatment and lack of specificity which causes toxicity and side effects. ${ }^{19}$

\section{ROLE OF NANOTECHNOLOGY IN TREATING LUNG CANCERS}

Nanoparticles have attracted attention to nano biomedical technology because of the presence of smaller size which has a huge amount of energy and allows the particle to adsorb and carry the hydrophilic and hydrophobic macromolecules to the target site. Nanoparticles are structured size ranging from 1 to $100 \mathrm{~nm}$. Various types of nanoparticles used are mentioned in Figure $1 .{ }^{20}$ Both the hydrophobic as well hydrophilic drug scan be encapsulated in nano structures which offer the controlled release of the drug. The nano carrier strategy is used for its accurate targeting which is highly important in targeted chemotherapy. Two Important mechanisms are followed for site-specific targeting i.e., active and passive mechanisms. ${ }^{21}$ Nanoparticles offers several advantages of include (a) Specific targeted drug delivery, (b) improves stability and
Table 1: USFDA approved drugs used for the treatment lung cancer.

\begin{tabular}{|c|c|c|}
\hline Drugs & Mechanism of action & Reference \\
\hline \multicolumn{3}{|c|}{ Non-small cell lung cancer } \\
\hline Abitrexate & $\begin{array}{l}\text { Inhibition of folic acid reductase, } \\
\text { which leads to inhibition of DNA } \\
\text { synthesis and cellular replication. }\end{array}$ & 9 \\
\hline Avastin & $\begin{array}{l}\text { Directly binds with VEGF to inhibit } \\
\text { angiogenesis. }\end{array}$ & 10 \\
\hline Carboplatin & $\begin{array}{l}\text { Activation enhances Inside cell which } \\
\text { forms reactive platinum complex. } \\
\text { Modifies DNA structure and inhibit } \\
\text { DNA synthesis. }\end{array}$ & 11 \\
\hline Docetaxel & $\begin{array}{l}\text { Inhibition of microtubule } \\
\text { depolymerisation and effect of bcl-2 } \\
\text { and bcl-xL gene expression. }\end{array}$ & 12 \\
\hline Gefitinib & $\begin{array}{c}\text { Inhibitor of EGFR tyrosine kinase } \\
\text { domain. }\end{array}$ & 13 \\
\hline \multicolumn{3}{|c|}{ Small cell lung cancer } \\
\hline Afinitor & $\begin{array}{l}\text { mTOR, mammalian target to } \\
\text { rapamycin }\end{array}$ & 14 \\
\hline Doxorubicin & $\begin{array}{c}\text { Interacts with DNA by intercalation } \\
\text { and inhibition of macromolecular } \\
\text { biosynthesis. }\end{array}$ & 15 \\
\hline Folex & $\begin{array}{l}\text { Inhibition of DNA and RNA and } \\
\text { protein synthesis results relatively } \\
\text { irreversible binding with di-hydro } \\
\text { folate reductase. }\end{array}$ & 16 \\
\hline Methotrexate & $\begin{array}{l}\text { Inhibits DHFR, an enzyme which } \\
\text { involves tetra-hydro folate synthesis. }\end{array}$ & 17 \\
\hline $\begin{array}{c}\text { Topotecan } \\
\text { Hydrochloride }\end{array}$ & $\begin{array}{l}\text { Exert its cytotoxic effects during the } \\
\text { s-phase of DNA synthesis. }\end{array}$ & 18 \\
\hline
\end{tabular}

VEGF: Vascular endothelial growth factor, bcl-2; B-cell lymphoma 2, EGFR; Epidermal growth factor receptor, mTOR; Mammalian Target of Rapamycin, DHFR; dihydrofolate reductase.

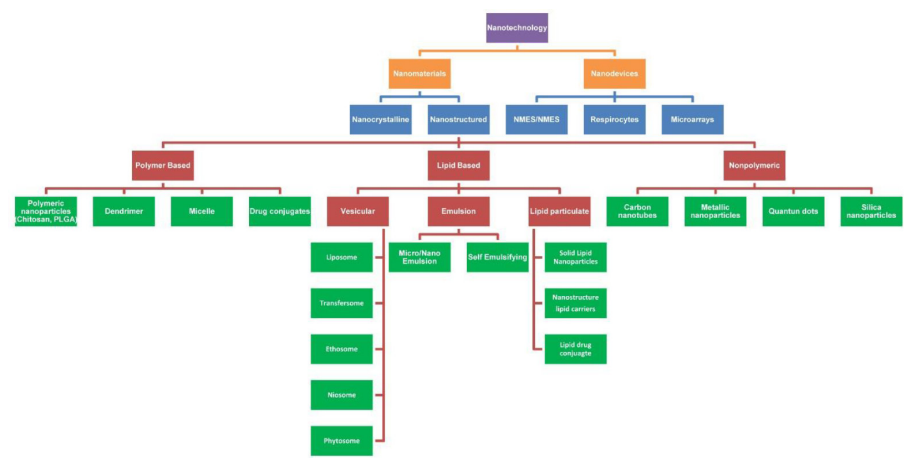

Figure 1: Classification of Nanoparticles.

eradicates toxicity, (c) both active and passive drug targeting can be achieved by reducing the size, (d) controlled release drug delivery, (e) better image and diagnostic tool for the earlier detection of cancer cells in biological system. (f) Less amount of dosage form is required, (g) more rapid onset of therapeutic action. There are three types nanoparticles have been used in the treatment of the Lung cancer (a). Natural and semi-synthetic nanoparticles, (b). Synthetic (organic) Nanoparticles, (c). Synthetic (In-Organic) Nanoparticles. 


\section{NATURAL AND SEMI-SYNTHETIC NANO- PARTICLES}

\section{Virus Nanoparticles}

The term virus describes the pathogens and generally are of two type Mammalian Virus and Plant Virus with the size range of 20-400 nm. The genetic material of the virus is protected by the protein coating known as capsid. Basically, the virus capsid nano-particles are non-replicated and non-infectious. The virus capsid vectors are of five types (a) Cowpea Mosaic Virus (CPMV), (b) Tobacco Mosaic Virus (TMV), (c) Cowpea chlorotic mottle virus, (d) Canine parvovirus, (e) Bacteriophages (QB) and Bacteriophage MS2. This particle has the capacity to withstand extreme temperature, $\mathrm{pH}$, and harsh chemicals. Their structure is symmetrical, polyvalent and Mono-dispersed and able to conjugate with various moieties like drugs, target specific reagent, Probe image of various inorganic nanoparticles. Most commonly CPMV is used in wide range vectors and shows icosahedrons shape with size approximately $28.4 \mathrm{~nm}$. And contain nearly 60 subunits which help to withstand the temperature of about $60^{\circ} \mathrm{C}$ and $\mathrm{pH}$ range from 3-9.22 The CPMV has the potential for in-situ vaccination in lung cancer therapy. ${ }^{22}$

\section{Liposomes and Solid Lipid Nanoparticles Liposomes}

The liposome is basically defined as the lipid bilayer or membraneenclosed vehicle. ${ }^{23}$ Liposomes composed of phospholipids, phosphatidylcholine, and cholesterol and the characteristics depend on the nature of the ingredients. The liposomes are used as non-viral carrier for drug and macromolecule for targeting wide variety of cells. Presently only two liposomal products are available in the market approved by USFDA namely (a) DOXIL for ovarian cancer and (b) Marqibo for lymphoblastic leukaemia. ${ }^{24}$ For the management of the Non-cell lung cancer liposome formulation are very limited compared with other cancer drug formulation. The Boulikas team developed lipoplatin containing of liposome and cisplatin which drastically reduces the nephrotoxicity in rats. Lipoplatin which showed a good result of clinical trials in $2014,{ }^{25}$ is a future hope for lung cancer. Another clinical trial of Paclitaxel (PTX) liposome cleared phase-I clinical trials to improve the therapy and reduce the drug resistance. ${ }^{26}$ Taetz et al. 2009 studied the effect of chitosan content in cationic chitosan/ PLGA nanoparticles for delivery efficiency of antisense 2'-O-methylRNA (2OMR) against telomerase in lung cancer cells. Tailorable cationic chitosan/PLGA nanoparticles (CPNP) were directed against RNA template of human telomerase and influence the binding efficiency, complex stability, uptake in different human lung cell. The efficacy of this Nanoplexes system were described CPNPs were prepared by the emulsionsolvent evaporation method using different amounts of chitosan and purified by preparative size exclusion chromatography. A small increase in size and an increase of zeta potential with increasing amounts of chitosan were found while characterizing using photon correlation spectroscopy and zeta potential measurements. Binding efficiency and complex stability with 2OMRwas high in water and correlated well with the chitosan content of particles but was weak in physiologically relevant media (PBS and RPMI cell culture medium). Flow cytometry analysis showed that the uptake of 2OMR into A549 lung cancer cells was considerably higher in combination with nanoparticles and dependent on the amount of chitosan when compared to 2OMR alone. Confocal laser scanning microscopy revealed that the uptake into A549 cells was mediated via complexes of $2 \mathrm{OMR}$ and chitosan/PLGA nanoparticles despite the weak binding in cell culture medium. The nanoparticles were well tolerated and effective in inhibiting telomerase activity. ${ }^{27}$

Rajani B et al. 2013 studied about the etoposide loaded solid lipid nanoparticles for curtailing B16F10 melanoma colonization in the lung.
In their study it was revealed that etoposide suffers poor solubility and poor bioavailability problems, but small lipid nanoparticles improved efficacy and therapy of metastasized cancer. The modulation of therapeutic activity was studied by performing an anti-mitotic activity on a B16F10 melanoma mouse model. Various in vivo and in vitro studies were also performed by them which show increased bioavailability and half-life and also enhancement in the ratio of the drug that reaches to the highly perfused organ. ${ }^{28}$

Shenbagamoorthy Sundarraj et al. 2014 studied Nebulizable colloidal nanoparticles co-encapsulating COX-2 inhibitors for the treatment of lung cancer. In their work PLGA nanoparticles were taken as a colloidal carrier for drugs with anti-cancer activity. Their study shows that naringin and celecoxib have high cytotoxic activity on A549 lung cancer cell lines. The PLGA nanoparticles were also characterized by particles size, entrapment efficiency, in vitro release, cytotoxicity, and aerosolization and nebulization behaviours. The results show that the PLGA nanoparticles with naringin and celecoxib show good controlled release profile also the high distribution of the drug in bones, brain, and liver which are the common metastatic sites of lung cancer. ${ }^{29}$

\section{Solid Lipid Nano-Particle (SLN)}

The solid lipid nanoparticle is submicron colloidal carriers which are composed of physiological lipid, dispersed in water or aqueous surfactant solution with the normal size ranges from 50-1000 nm. The solid lipid nanoparticles made up of triglycerides, Cetyl alcohol, beeswax, cholesterol. ${ }^{30}$ The SLN is quite more stable than liposome in a biological system. Considering the dimensions in the nanometre range of the SLN said to be a zero-dimensional nanomaterial. The SLN is used as the colloidal carrier of hydrophobic chemotherapeutic for long circulation of the bloodstream. Cationic SLN is amphiphilic nature where the presence of two hydrophobic fatty acid chain and hydrophobic amino group with the linker. ${ }^{31}$

The hydrophobic amino acid interacts with negatively charged DNA plasmid to form a stable complex. The cationic SLN complex induces into damaged area either by intra-tracheal installation method or aerosol inhalation. ${ }^{32}$ In this era researchers successfully loaded Bcl-2-siRNA, PTX and CdSe /ZnS in Solid lipid nanoparticles (Quantum Dots). The major advantage of the SLN is leakage of the drug into the bloodstream is very low compared to the liposome formulation and enhanced the circulation rate in blood with controlled release.

\section{Chitosan}

Generally, the chitosan is prepared by N-deacetylation of chitosan where it is biodegradable cationic and nitrogenous polysaccharides. Chitosan are crystalline micro fibrils structure which can be found in the exoskeleton of arthropods. The chitosan has the primary unit as 2-deoxy-2-(acetylamino) glucose fond in various microorganism and fungi and has the capacity of exhibiting muco-adhesive nature. The ionic force gradient between the chitosan-cell acts as the driving force to permeate into epithelial cells. The degree of degradation (DD) plays the major role in differentiating the chitin and chitosan. N-deacetylation is the core derivative of chitosan. In chitosan, if DD is less than $40 \%$ it is poorly insoluble in water, because due to H-bonds between amide, alcohol functional distributed in the repeating units along the polymeric chain and hydrophobic interactions. If DD is more $40 \%$ it became soluble in acidic condition. Chitosan is insoluble in most of the solvents but, it is soluble in most of the $\mathrm{pH}$ range from between 6.5 organic acids like acetic, tartaric, phosphoric acid. The chitosan is associated with the copolymer family of various divisions of acetylated units. ${ }^{33}$ It has the huge capacity of readily degradable in lung cells through lysozyme.

The formulation of chitosan done through a modified generation where based on the electrostatic interaction of two group such as (a) Amine 
group of chitosan and (b) negative group of the polyamine. During formulation, the ratio plays the vital role in size of the chitosan nanoparticles. The unique characteristic of chitosan is non-toxic, renewable, high affinity to proteins, modification of cell wall permeability.

Rahul Pratap Singh et al. 2017 developed chitosan folate conjugated Digitoxin (DTX) loaded Multi wall carbon nanotube (MWCNT) in effective manner for lung cancer. They made two different formulation Digitoxin non-conjugated (DTX-CNAC) and Digitoxin chitosan conjugated DTX-CHI-CNAC The Chitosan folate formulation achieved the drug entrapment efficacy nearly $79 \%$ with the particle size range of $230-483 \mathrm{~nm}$. The in vitro shows the promising controlled release of MWCNT. The cytotoxicity study shows significant intracellular concentration and elevated cellular uptake of MWCNT. The DTX-chitosan folate achieved 89 folds of the drug efficacy in $\mathrm{IC}_{50}$ value which is compared with the marketed product DOCEL ${ }^{\mathrm{na}}$ by incubating in A549cell. Both DTX-CNAC and DTX-CHI-CNAC show the low toxicity and promise the effective platform for targeting the drug in lung cancer. ${ }^{34}$

Ana Vanessa Nascimento et al. 2016 developed a new epidermal growth factor receptor (EGFR)-chitosan drug targeting for the non-small cell lung cancer (NCSLC). They combined Mad2 siRNA and cisplatin showed maximum therapeutic efficacy by crossing the chemo-drug resistance barrier in NCSLC. The optimized two formulation shows target delivery in more effective way and high retention. Observation indicates that the combination of Mad2SiRNA significantly lowers the cell growth and mitotic failure specifically for the high proliferating cells. They observed that the EGFR chitosan carrier helps the siRNA for the better targeting action. ${ }^{35}$

\section{Synthetic (organic) Nanoparticles Polymer Nanoparticles (PNS)}

The polymeric nanoparticle (synthetic) shows good result to releasing the anti-neoplastic drug in lungs in a control manner to enhance the therapeutic efficacy prolong the systemic circulation and acting as site specific manner. ${ }^{36}$ Polymeric nanoparticles are one of the good candidates to administrate through both intravenous and oral route. Various polymers are used in the preparation of the PNS such as Poly (lactic acid) (PLA), Poly (glycolic acid) (PLA), Poly (lactic-co-glycolic) acid (PLGA), Poly (amino acid), Poly alkyl cyanoacrylates. The PNS is further categorized into two micelles format (a) Spherical Polymer Micelles, (b) Worm-like Polymer Micelles. The drug delivery of polymer Nano-particles are generally worked on two major steps (a) Polymer Nano-spheres, (b) Polymer Nano-capsules.

USFDA has approved PLGA Nanoparticles which are more effective against carcinoma cells the amended into a formulation that shows the good tumor suppressor, biomolecule to A549 lung cancer cell. PLGA is more suitable for the target delivery and it has more circulation time in the bloodstream and less renal clearance. ${ }^{37}$

Jung et al. 2012 reported that the PEG-modified poly nanoparticles which are incorporated in addition to Taxanes show good chemo-radiotherapy to A549 cells in the xenograft model in both in vitro and in vivo in lung cancer. Sengupta et al. 2005 studied the PLGA nanoparticles enveloped inside PEGylated-Phospholipid block copolymer. They worked on two parts where first with cytoskeletal structure and eradication of cancer cells. They completely trapped the anti-angiogenesis agent combretastatin-A4 inside the lipid envelope and conjugated cytotoxic agent DOX to PLGA nanoparticles core. When the nanoparticles reach the targeted site the outer layer of the phospholipid breaks and release the anti-angiogenic which completely changes the cytoskeletal structure followed by the core PLGA nanoparticles escapes from the inner core and kills the neoplastic cells completely in NSCLC in mice. ${ }^{38}$
Georgi Yordanov et al. 2012 carried out a study for the preparation of epirubicin-loaded Nanoparticles. It was prepared by loading the drug in the pre-polymerized poly (butyl cyanoacrylate). Nanoparticles it was coated to from an aqueous dispersion with two different non-ionic surfactants (Pluronic F68 and Polysorbate 80). Human lung adenocarcinoma (A549) cells were used to carry out the physicochemical characterization and in vitro evaluation. The particles were of a uniform shape and size the increase in drug content increased the zeta-potentials at $\mathrm{pH}$ 7.4. The in vitro studies were done in A549 cells and the cytotoxicity was studied and the results concluded that the presence of surfactants increased the cytotoxicity. Fluorescent imaging was done in the adenocarcinoma cells with epirubic in in internalization which revealed showed that the free drug was predominantly localized in the cell nucleus, whereas the cytoplasmic localization was observed in the nanoparticle-bound drug formulations, which suggested the probability of the nanoparticle endocytosis. Thus, they concluded that the results could be useful in the development of nanoparticle-based anthracycline formulations of treatment of lung adenocarcinoma. ${ }^{39}$

N Nafee et al. 2012 aimed to develop chitosan nanoparticles loaded Antisense oligonucleotide, 2-O-Methyl-RNA (OMR) a telomerase inhibitor for treating lung cancer. In this research, they studied the properties of chitosan and tried to improve the concentration of the viability, cellular uptake, and telomerase inhibition in human lung cancer cell lines. To improve the transfection the charges can't be considered as the important factor. The uptake studies were carried out on air-interface cell cultures to mimic the in vivo conditions, which showed the enhanced uptake of nano-plexes over the naked oligonucleotide. The OMR nanoplexes reduced the telomerase activity by $50 \%$ in A549 cells. They concluded that the potential for the system was safe, non-invasive, and an effective treatment for lung. ${ }^{40}$

Ramy Said-Elbahr et al. 2016 studied about ligand conjugated mesoporous silica nanoparticles based on the enzyme targeted prodrug delivery system. Their study shows that silica nanoparticles are non-toxic and used for targeted drug delivery for cancer therapy. Their study also shows that silica nanoparticles and EGFRAb SN-pyrrolidine - 2 exhibits low systemic toxicity in Balb/c mice and high therapeutic activity. ${ }^{41}$

Iavicolia et al. 2017 studied about in vitro evaluation of potential toxic effects of palladium nanoparticles on fibroblasts and lung epithelial cells. In this, they have studied the toxicological mechanisms of Palladium (Pd) nanoparticles and their effects on normal diploid rat fibroblast and lung carcinoma human epithelial cell lines. The results have shown that palladium nanoparticles inhibit cell growth and enhance the action on fibroblast. ${ }^{42}$

\section{OTHER CASE STUDIES}

Xiaolu Yin et al. 2004 have done a research on the topic anti-cancer activity and mechanism of Scutellarin barbets extract from human lung cancer cell line A549. S Barbara, a southern Chinese traditional plant which has good anti-inflammatory and diuretic activity. This plant had shown growth inhibitory effect on various human cancers. They used A549 lung cancer cell line to study the growth inhibitory effect of s. Barbata and their results showed that ethanol extracts from S. barbets greatly inhibited A549 cell growth, with $\mathrm{IC}_{50}$ of $0.21 \mathrm{mg} / \mathrm{ml}$. Cell apoptosis and cytotoxic effects were the mechanisms of inhibitory action cDNA microarray analysis studied in 16 genes, which involved in DNA damage, cell cycle control, nucleic acid binding and protein phosphorylation. Undergone more than 5-fold change the data indicated that these processes were involved in s. Barbata mediated killing of cancer cells. ${ }^{43}$ Janne Lehtio et al. 2010 discussed the importance of proteomic technology in the Lung cancer. Their work was about the discovery of relevant 
biomarkers which can be accurately quantified in multiplex assays. Their work specifically carried out in the field of Lung cancer proteomics. ${ }^{44}$

Jingwei Ma et al. 2010 had explained about the (Synthesis of magnetic and fluorescent bifunctional Nano composites and their applications in detection of lung cancer cells in humans) they developed a novel diagnostic tool to detect lung cancer by using the Magnetic and Fluorescent bifunctional Nano composites (BNPS) in combination with leukemia anti-carcinoembryonic antigen (CEA) antibodies. In that method, they have explained about the silica-coated super magnetic Nanoparticles and quantum dots exhibits high luminescence and easily separated by the external magnetic field. They also demonstrated that as-prepared immune nanoparticles can capture and detect the cancer cells in pleural effusion from lung cancer by their experiments. ${ }^{45}$

Julie Todoroff et al. 2011 they explained the fate of Nano medicines in the lung is highly based on physic-chemical and biological properties of the compound used. The IgG Antibodies is endocytosis by alveolar macrophages and transported across respirator epithelia by receptor-mediated endocytosis and insulin was not taken up by the alveolar macrophages and crosses the epithelium towards systemic circulation by paracellular diffusion. Any inhale particles can be easily cleared from the lung within $24 \mathrm{~h}$ whereas the Nanoparticles escape by the lung surface macrophages and can remain for weeks with translocation across respiratory epithelia. ${ }^{46}$ Oleh Tarantula et al. 2010 explained that a tumor-targeted Mesoporous Silica Nanoparticles (MNS) drug delivery system is capable of delivering to incise cancer cells. The anti-cancer drugs (Doxorubicin and Cisplatin) combined with two types of siRNA targeted to MRP 1 and BCL2 mRNA. These two types were used for both the pump and non-pump cellular resistance of non-small cell lung carcinoma respectively. The MSN targeting is achieved by LHRH peptide conjugation on the surface of MSN by a poly spacer (ethylene glycol). They explained that siRNA effectively delivered inside cancer cells and enhanced the cytotoxicity of anti-cancer drugs. They described that the MSN by pulmonary delivery is preferred as, in the mouse lungs, prevented the escape of MSN into the systemic circulation and also into other organs. Therefore, they suggested to MSN as it has the high potential for the effective treatment of lung cancer. ${ }^{47}$

Kaustubh et al. 2012 studied the liposomal formulation which consists of etoposide and docetaxel which has the capacity to eradicate p53 elevated cytotoxicity ion lung cancer. They prepared the dry powder formulation of dry powder which helps to deposit on the lungs. They parallelly did the comparative study on non-small cell lung cancer cell line with the pre-treatment and co-administration of the p56 cancer suppressor gene. They formulated two type of delivery liposomes and lipoplexes which is generally made up of cationic they underwent cellular uptake and shows cytotoxicity nearly $13-28 \%$, on another hand when the p53 is co-administered they observed the elevated cytotoxicity $41-63 \%$.the lipoplexes had the size range of $200-350 \mathrm{~nm}$, zeta potential $5-32 \mathrm{mv}$ and it has the delayed release 16-24h. In that study, they sensitized the cell once after the $\mathrm{p} 53$ pre-treatment is done and followed by the co-administration shown the significant in $\mathrm{H} 1299$ cell line. ${ }^{48}$

\section{CONCLUSION}

Nanoparticles due to their small size and high invasive property will invade into cancer cells and can effectively treat cancers. The above discussed literature shows that various types of nanoparticles have been extensively studied in treating lung cancers. However, many of these results are still at preclinical stages and these nanoparticles have to show their safety and efficacy in clinical trials and further their use in clinics.

\section{AUTHOR'S CONTRIBUTION}

Raahulan Sivarajakumar, Dhamini Mallukaraj, Madhurya Kadavakollu, Niveditha Neelakandan, Sandhya Chandran, Saravanan Bhojaraj were the lead authors and synthesized the literature and involved in drafting the paper. Karri V V S R provided conceptual input, design and critical revision of the manuscript. All authors read and approved the final paper.

\section{ACKNOWLEDGEMENT}

The authors would like to that thank JSS Academy of Higher Education and Research for providing necessary facilities to write this article.

\section{CONFLICT OF INTEREST}

The authors declare that there are no conflicts of interest involved in this study. The authors alone are responsible for the content and writing of the paper.

\section{ABBREVIATIONS}

AD: Adenocarcinoma; SCC: Squamous cell carcinoma; LC: Large cell carcinoma; VEGF: Vascular endothelial growth factor; bcl-2: B-cell lymphoma 2; EGFR: Epidermal growth factor receptor; mTOR: Mammalian Target of Rapamycin; DHFR: dihydrofolate reductase; IV: Intravenous therapy; Nm: Nano meter; CPMV: Cowpea Mosaic Virus; TMV: Tobacco Mosaic Virus; QB: Bacteriophages; 2OMR: 2'-O-methyl- RNA; SLN: Solid lipid nanoparticles; PTX: Paclitaxel; DD: degree of degradation; DTX: Digitoxin; EGFR: epidermal growth factor receptor; MWCNT: Multi wall carbon nanotube; PLA: Poly (lactic acid); PLGA: Poly (lacticco-glycolic) acid; OMR: 2-O-Methyl-RNA; BNPS: bifunctional Nano composites; CEA: anti-carcinoembryonic antigen; MNS: Mesoporous Silica Nanoparticles.

\section{REFERENCES}

1. Edwards BK, Noone AM, Mariotto AB, Simard EP, Boscoe FP, Henley SJ, et al. Annual Report to the Nation on the status of cancer, 1975 to 2010, featuring prevalence of comorbidity and impact on survival among persons with lung, colorectal, breast, or prostate cancer. Cancer. 2014;120(9):1290-314.

2. Armitage $P$, Doll R. The age distribution of cancer and a multi-stage theory of carcinogenesis. Br J Cancer. 1954;8(1):1.

3. http://www.cancerresearchuk.org/about-cancer.html

4. Pujol JL, JacotW, Boher JM, Quantin X. Pathology of Lung Cancer.

5. Travis WD, Lubin J, Ries L, Devesa S. United States lung carcinoma incidence trends: declining for most histologic types among males, increasing among females. Cancer. 1996;77(12):2464-70.

6. Thunnissen E, Noguchi M, Aisner S, Beasley MB, Brambilla E, Chirieac LR, et al. Reproducibility of histopathological diagnosis in poorly differentiated NSCLC: An international multiobserver study. J Thorac Oncol. 2014;9(9):1354-62.

7. Rani D, Somasundaram VH, Nair S, Koyakutty M. Advances in cancer nanomedicine. J. Indian Inst Sci. 2012;92(2):187-218.

8. Dolmans DE, Fukumura D, Jain RK. Photodynamic therapy for cancer. Nat Rev Cancer. 2003;3(5):380.

9. Https: //www.edudrugs.com/A/Abitrexate/more.html.

10. Mukherji SK. Bevacizumab (avastin). AJNR. 2010;31(2):235-6.

11. Sousa GF, Wlodarczyk SR, Monteiro G. Carboplatin: Molecular mechanisms of action associated with chemo resistance. BJPS. 2014;50(4):693-701.

12. Herbst RS, Khuri FR. Mode of action of docetaxel-a basis for combination with novel anticancer agents. Cancer Treat Rev. 2003;29(5):407-15.

13. Lenz HJ. Anti-EGFR mechanism of action: Antitumor effect and underlying cause of adverse events. Oncology (Williston Park, NY). 2006;20(5):5-13.

14. http://www.centerwatch.com/drug-information/fda-approved drugs/drug/1212/ afinitor-everolimus.html

15. Jackson TL. Intracellular accumulation and mechanism of action of doxorubicin in a spatio-temporal tumor model. J Theor Biol. 2003;220(2):201-13.

16. https://www.drugs.com/mmx/folex.html

17. Tian $\mathrm{H}$, Cronstein BN. Understanding the mechanisms of action of methotrexate. Bull NYU Hosp Jt Dis. 2007;65(3):168-73.

18. Palchaudhuri R, Hergenrother PJ. DNA as a target for anticancer compounds: methods to determine the mode of binding and the mechanism of action. Curr 
Opin Biotechnol. 2007;18(6):497-503.

19. Schmid G. Nanoparticles. Wiley VCH. 2005:63.

20. Alivisatos AP. Semiconductor clusters, nanocrystals, and quantum dots. Science. 1996;271(5251):933-7.

21. Feng B, Hong RY, Wang LS, Guo L, Li HZ, Ding J, et al. Synthesis of Fe3O4/APTES/PEG diacid functionalized magnetic nanoparticles for MR imaging. Colloids Surf A. 2008;328(1-3):52-9

22. Robertson KL, Soto CM, Archer MJ, Odoemene O, Liu JL. Engineered T4 viral nanoparticles for cellular imaging and flow cytometry. Bioconjug Chem. 2011;22(4):595-604.

23. Caruso G, Caffo M, Alafaci C, Raudino G, Cafarella D, Lucerna S, et al. Could nanoparticle systems have a role in the treatment of cerebral gliomas. Nanomedicine. 2011;7(6):744-52.

24. Babu A, Templeton AK, Munshi A, Ramesh R. Nanoparticle-based drug delivery for therapy of lung cancer: Progress and challenges. J Nanomater. 2013;2013:14.

25. Liposomal cisplatin (Nanoplatin) for advanced non-small cell lung cancer-first line. 2012. http://www.hsc.nihr.ac.uk/topics/liposomal-cisplatin-nanoplatin-foradvanced-non-sm/html

26. KrishnamachariY, Geary SM, Lemke CD, Salem AK. Nanoparticle delivery systems in cancer vaccines. Pharm Res. 2011:28(2):215-36.

27. Taetz S, Nafee N, Beisner J, Piotrowska K, Baldes C, Mürdter TE, et al. The influence of chitosan content in cationic chitosan/PLGA nanoparticles on the delivery efficiency of antisense 2'-O-methyl-RNA directed against telomerase in lung cancer cells. Eur J Pharm Biopharm. 2009;72(2):358-69.

28. Athawale RB, Jain DS, Singh KK, Gude RP. Etoposide loaded solid lipid nanoparticles for curtailing B16F10 melanoma colonization in lung. Biomed Pharmacother. 2014;68(2):231-40

29. Sundarraj S, Thangam R, Sujitha MV, Vimala K, Kannan S. Ligand-conjugated mesoporous silica nanorattles based on enzyme targeted prodrug delivery system for effective lung cancer therapy. Oxicol Appl Pharmacol. 2014;275(3):232-43.

30. Barthelemy P, Laforet JP, Farah N, Joachim J. Compritol® 888 ATO: An innovative hot-melt coating agent for prolonged-release drug formulations. Eur J Pharm Biopharm. 1999;47(1):87-90.

31. Mathur V, Satrawala Y, Rajput MS, Kumar P, Shrivastava P, Vishvkarma A. Solid lipid nanoparticles in cancer therapy. Int J Drug Deliv. 2010;2(3):192-9.

32. Zou Y, Zong G, Ling YH, Hao MM, Lozano G, Hong WK, et al. Effective treatment of early endobronchial cancer with regional administration of liposome-p53 complexes. J Natl Cancer Inst. 1998;90(15):1130-7.

33. Kumar MN. A review of chitin and chitosan applications. React Funct Polym. 2000;46(1):1-27

34. Singh RP, Sharma G, Singh S, Bharti S, Pandey BL, Koch B, et al. Chitosan-folate decorated carbon nanotubes for site specific lung cancer delivery. Mater Sci Eng C. 2017;77:446-58.
35. Nascimento AV, Singh A, Bousbaa $H$, Ferreira D, Sarmento B, Amiji MM. Overcoming cisplatin resistance in non-small cell lung cancer with Mad2 silencing siRNA delivered systemically using EGFR-targeted chitosan nanoparticles. Acta Biomater. 2017:47:71-80.

36. Allouche J. Synthesis of organic and bioorganic nanoparticles: An overview of the preparation methods. In Nanomaterials: A Danger or a Promise. 2013;27-74.

37. Chan JM, Zhang L, Yuet KP, Liao G, Rhee JW, Langer R, et al. PLGA-lecithin-PEG core-shell nanoparticles for controlled drug delivery. Biomaterials. 2009;30(8):1627-34.

38. Jung J, Park SJ, Chung HK, Kang HW, Lee SW, Seo MH, et al. Polymeric nanoparticles containing taxanes enhance chemoradiotherapeutic efficacy in non-small cell lung cancer. Int J Radiat Oncol Biol Phys. 2012;84(1):77-83.

39. Yordanov G, Evangelatov A, Skrobanska R. Epirubicin loaded to pre-polymerized poly (butyl cyanoacrylate) nanoparticles: preparation and in vitro evaluation in human lung adenocarcinoma cells. Colloids and Surfaces B: Biointerfaces. 2013:107:115-23.

40. Nafee N, Schneider M, Friebel K, Dong M, Schaefer UF, Mürdter TE, et al. Treatment of lung cancer via telomerase inhibition: self-assembled nanoplexes versus polymeric nanoparticles as vectors for 2'-O-Methyl-RNA. Eur J Pharm Biopharm. 2012;80(3):478-89

41. Said-Elbahr R, Nasr M, Alhnan MA, Taha I, Sammour O. Nebulizable colloidal nanoparticles co-encapsulating a COX-2 inhibitor and a herbal compound for treatment of lung cancer. Eur J Pharm Biopharm. 2016;103:1-2.

42. Iavicoli I, Farina M, Fontana L, Lucchetti D, Leso V, Fanali C, et al. In vitro evaluation of the potential toxic effects of palladium nanoparticles on fibroblasts and lung epithelial cells. Toxicology in vitro. 2017;42:191-9.

43. Yin $X$, Zhou J, Jie C, Xing D, Zhang Y. Anticancer activity and mechanism of Scutellariabarbata extract on human lung cancer cell line A549. Life sciences. 2004;75(18):2233-44.

44. Lehtiö J, De Petris L. Lung cancer proteomics, clinical and technological considerations. J Proteom. 2010;73(10):1851-63.

45. Ma J, Fan Q, Wang L, Jia N, Gu Z, Shen H. Synthesis of magnetic and fluorescent bifunctional nanocomposites and their applications in detection of lung cancer cells in humans. Talanta. 2010;81(4-5):1162-9.

46. Todoroff J, Vanbever R. Fate of nanomedicines in the lungs. Curr Opin. Colloid Interface Sci. 2011;16(3):246-54

47. Taratula O, Garbuzenko OB, Chen AM, Minko T. Innovative strategy for treatment of lung cancer: Targeted nanotechnology-based inhalation co-delivery of anticancer drugs and siRNA. J Drug Target. 2011;19(10):900-14.

48. Jinturkar KA, Anish C, Kumar MK, Bagchi T, Panda AK, Misra AR. Liposomal formulations of Etoposide and Docetaxel for p53 mediated enhanced cytotoxicity in lung cancer cell lines. Biomaterials. 2012;33(8):2492-507.

Article History: Submission Date : 19-03-2018; Revised Date : 04-05-2018; Acceptance Date : 08-06-2018.

Cite this article: Sivarajakumar R, Mallukaraj D, Kadavakollu M, Neelakandan N, Chandran S, Bhojaraj S, Karri VVSR. Nanoparticles for the Treatment of Lung Cancers. J Young Pharm. 2018;10(3):276-81. 